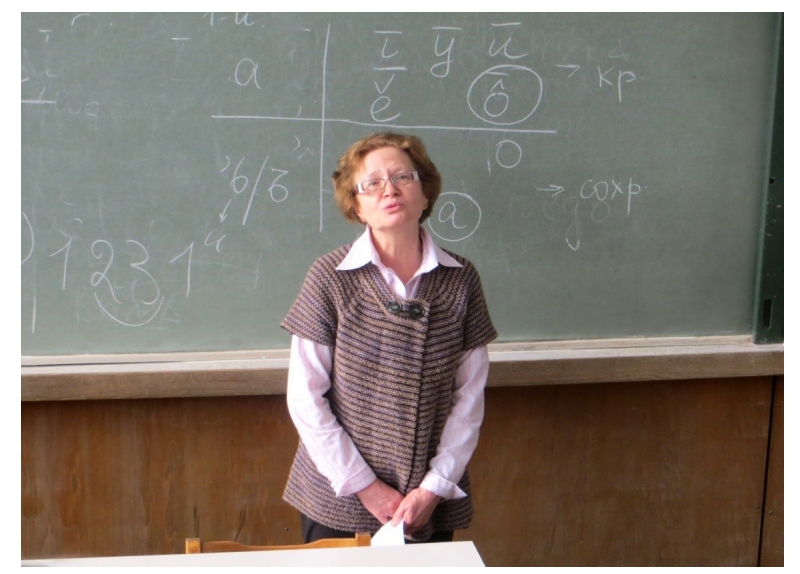

\section{Международная научная конференция «Шведский стол - Smörgåsbordet», посвященная юбилею профессора Е.М. Чекалиной}

(7-8 октября 2021 г., кафедра германской и кельтской филологии, филологический факультет МГУ имени М.В. Ломоносова)

\title{
International Scientific Conference «Swedish Table - Smörgåsbordet» Dedicated to the Anniversary of Professor E.M. Chekalina
}

(October 7-8, 2021, Department of Germanic and Celtic Philology, Philological Faculty, Lomonosov Moscow State University)

Кафедра германской и кельтской филологии отмечает юбилей заведующего кафедрой профессора Е.М. Чекалиной организацией и проведением Международной научной конференции-круглого стола «Шведский стол - Smörgåsbordet», в котором принимают участие коллеги, друзья и ученики Елены Михайловны, работающие в разных научных, культурных и учебных центрах России, а также гости и коллеги из Швеции и Латвии. Круглый стол пройдет 7 и 8 октября 2021 г. в онлайн-формате, на заседаниях будет представлено 33 доклада, охватывающих самый широкий спектр вопросов - начиная от историко-культурных, филологических и общегерманистических, и заканчивая более частными, касающимися функционирования и преподавания конкретных языков (см. ниже резюме докладов). Рабочими языками конференции являются русский, шведский, английский языки.

На конференции прозвучат приветствия Елене Михайловне от скандинавистов, представляющих крупнейшие Российские вузы: Санкт-Петербургский государственный университет (и.о. зав. кафедрой скандинавской и нидерландской филологии СПбГУ профессор И.М. Михайлова, доцент Е.В. Краснова, доцент А.В. Савицкая), Московский государственный лингвистический университет (зав. кафедрой скандинавских, нидерландского и финского языков переводческого факультетата МГЛУ до- 
цент Е.В. Воробьева), Российский государственный гуманитарный университет (директор Российско-шведского учебно-научного центра РГГУ, доцент, почетный доктор Уппсальского ун-та Т.А. Тоштендаль-Салычева), а также Институт повышения квалификации «Высшие курсы иностранных языков МИД РФ» (доцент В.М. Сапронова). От Посольства королевства Норвегия Елену Михайловну поздравит выпускница кафедры германской и кельтской филологии, координатор Отдела культуры посольства и переводчик Е.С. Рачинская. К поздравлениям присоединятся известные переводчики и выпускники кафедры: член Союза писателей России Т.А. Чеснокова и ведущий редактор издательства «Синдбад» Е.М. Чевкина. От зарубежных коллег Е.М. Чекалину поздравят лекторы Шведского Института Х. Вестман и А. Ульссон, в различное время преподававшие шведский язык студентам кафедры германской и кельтской филологии.

Коллектив кафедры германской и кельтской филологии сердечно поздравляет Елену Михайловну Чекалину с юбилеем. С этой кафедрой (до 2005 г. она называлась кафедрой германского языкознания) неразрывно связана жизнь Елены Михайловны. Поступив в 1964 г. на филологический факультет, на этой кафедре она учила шведский язык, защитила кандидатскую, а потом и докторскую диссертацию. Здесь с 1972 г. Елена Михайловна преподает шведский язык, пройдя путь от младшего научного сотрудника до заслуженного профессора Московского университета, бессменного заведующего кафедрой.

Сфера научных интересов Елены Михайловны необычайно широка. Ей интересны системно-функциональные и типологические особенности шведской грамматики, перевод, лексикология и лексикография, история языка и многое-многое другое, что нашло отражение в ее трудах, посвященных самым разным аспектам изучения шведского языка. Названия работ Е.М. Чекалиной наглядно демонстрируют широту и многообразие ее научных интересов:

Чекалина E.M. Грамматика шведского языка (на шведском языке). М.: Изд-во Моск. ун-та, 1984.

Чекалина E.M. Хрестоматия по истории шведского языка: тексты, комментарии, этимологический словарь. М.: Изд-во Моск. ун-та, 2004.

Чекалина Е.М., Жильцьова Е.Л. и др. Русский словарь издательства «Норстедтс». Русско-шведский. Шведско-русский. 141.000 слов и словосочетаний. 1-е изд., вып. первый. Стокгольм: Norstedts Akademiska Förlag. 2006.

Чекалина Е.М., Жильцьова Е.Л. Шведский язык. Справочник по грамматике. М.: Живой язык, 2009.

Чекалина Е.M. Шведский язык. Справочник по глаголам. М.: Живой язык, 2009.

Чекалина E.M. Семантические аспекты шведской грамматики. Саарбрюккен: LAP LAMBERT Academic Publishing Deutschland, 2015.

Чекалина E.M. Семантические аспекты шведской грамматики: системно-функциональный и сопоставительно-типологический анализ. Москва: МАКС Пресс, 2017.

И.В. Матьцина 


\title{
РЕЗЮМЕ ДОКЛАДОВ
}

\author{
Ю.М. Авакова (МГИМО МИД России) \\ НАЦИОНАЛЬНАЯ МОДЕЛЬ «МЯГКОЙ СИЛЫ» ДАНИИ \\ И КАЗУС КРИСТИАНАЭРИКСЕНА НА ЕВРО-2021
}

В докладе рассматривается социокультурный феномен «мягкой силы» на примере реакции на несчастный случай, произошедший с Кристианом Эриксеном, атакующим полузащитником национальной сборной Дании по футболу, 12 июня на Евро-2020 во время матча с Финляндией. Осмысление инцидента в датских и международных СМИ, а также комментарии лиц, причастных к работе в сборной, позволяют выявить определенные закономерности в отношении круга ценностей, имеющих первостепенное значение для датчан при столкновении с нештатными ситуациями. Существующий массив информации также дает возможность проследить, каким образом эта ситуация была использована не только для консолидации датского общества, но и для формирования и поддержания позитивного имиджа государства вовне, посредством «мягкой силы».

Н.С. Бабенко (Институт языкознания РАН)

\section{ФУНКЦИИ ЭЛЕМЕНТА ЕS В ИНФОРМАЦИОННОЙ СТРУКТУРЕ} ПРЕДЛОЖЕНИЯ НЕМЕЦКОГО ЯЗЫКА

Для обсуждения предлагаются механизмы «обезличивания» в немецком языке, маркером которого выступает элемент es. В фокусе внимания находятся разнообразные случаи включения элемента es в структуру высказываний, уровень облигаторности и вариативности употребления es, а также идиоматичности образований c es. Es pacсматривается как специфическое для строя немецкого языка явление синтаксического уровня и анализируются его трактовки в теоретических и лингводидактических работах. При рассмотрении предложений с элементом es в версии коммуникативного синтаксиса в фокус внимания попадают некоторые свойства данных образований, которые заложены в глубинной структуре, но оказываются достаточно отчетливо выраженными и на уровне поверхностной структуры.

Л.Э. Бюссель (L.E. Byssel; Шведский институт; МГУ имени М.В. Ломоносова)

12 чЕЛОБИТНЫХ ИЗ ИНГЕРМАНЛАНДИИ О РУССКИХ РУКОПИСЯХ, ХРАНЯЩИХСЯ В ГОСУДАРСТВЕННОМ АРХИВЕ ШВЕЦИИ

В представленной работе исследовался рукописный материал,состоящий из 12 русских челобитных, написанных в 1637 г. Стилистический анализ показал, что представленные челобитные по своей структуре, оформлению и языку соответствуют образцам, характерным для данного жанра. Морфофонетический анализ показал, что в представленных челобитных присутствуют черты, типичные для канцелярского регистра, и что в целом данные челобитные соответствуют языковой практике официальных текстов XVII в.

Полученные результаты соответствуют основным положениям теории развития русского письменного языка В.М. Живова.

Tolv suppliker från Ingermanland - om ett ryskt handskriftsmaterial funnet på svenska Riksarkivet Tolv suppliker från Ingermanland - om ett ryskt handskriftsmaterial fun- 
net på svenska Riksarkivet I arbetet analyseras ett handskriftsmaterial bestående av 12 ryska suppliker från 1637 utifrån stilistiska, fonetiska och morfologiska aspekter.

Den stilistiska analysen visar att supplikerna till sin struktur, utformning och sitt språk följer de förebilder som fanns inom genren. Den fonetiska och morfologiska analysen visar att det i supplikerna förekommer drag som var typiska för kansliregistret och att supplikerna överlag återspeglar 1600-talsnormen för kanslitexter.

V.M. Živovs teorier om det ryska skriftspråkets utveckling visar sig falla tämligen väl ut på supplikerna.

(Доклад на русском, презентация на шведском языке.)

М.А. Волконская (Национальный исследовательский университет

«Высшая школа экономики»)

ГРАНИЦЫ И ПРЕЕМСТВЕННОСТЬ: ШОТЛАНДСКОЕ СОЧИНЕНИЕ О ПЛОДАХ МЕССЫ И ЕГО ВОЗМОЖНЫЕ АНГЛИЙСКИЕ ИСТОЧНИКИ

Изменения в обряде католической мессы в XII-XIII вв. привели к появлению многочисленных рассказов о чудесах, которые могли быть дарованы мирянам в процессе созерцания Святых Даров. Списки этих плодов мессы (virtutesmissae) пользовались большой популярностью и были чрезвычайно распространены в Англии в XIV и $\mathrm{XV}$ вв. Сочинение, о котором пойдет речь в данном докладе, - это прозаический текст на скотс, записанный во второй половине XV в. Будучи достаточно самобытным, этот текст, однако, находит ряд параллелей в сочинениях, созданных в южном королевстве.

Н.А. Ганина (МГУ имени М.В. Ломоносова)

Codex Aureus (Стокгольм, Kungliga вiBLiOTEKeT, MSA. 135): к тИПОЛОГИИ И ИСТОРИИ РУКОПИСИ

Доклад посвящен рассмотрению типологических особенностей и истории одной из наиболее примечательных раннесредневековых иллюстрированных рукописей - Codex Aureus (Стокгольм, Kungliga biblioteket, MSA. 135). Этот кодекс, представляющий собой латинскую рукопись Четвероевангелия и отличающийся исключительной пышностью оформления, был создан в королевстве Кент в середине VIII в. В раннее Новое время кодекс оказался в Испании, где его в 1690 г. приобрел шведский дипломат и лингвист Юхан Габриэль Спарвенфельд (1655-1727), в 1705 г. передавший свою коллекцию рукописей Королевской библиотеке.

\section{Н.Ю. Гвоздецุкая (РГГУ; Сретенская духовная академия)}

\section{ОБРАЗЫ ЕПИСКОПОВ В ИСЛАНДСКОЙ ХРОНИКЕ ХIII ВЕКА НUNGRVAКА}

На материале исландской хроники XIII в. Hungrvaka «Пробуждающая [духовный] голод» рассматриваются способы изображения первых исландских епископов в их «портретных» характеристиках. Показано, что епископ воспринимался как глава местного клана со всеми его социальными и гендерными особенностями, сложившимися в эпоху викингов. Однако в «портрете» Торлака Рунольвссона, тезки Торлака Торхалльссона, первого национального святого Исландии, акцентируются христианские добродетели. 
ПОХВАЛА, КОМПЛИМЕНТ И ЛЕСТЬ В ДАТСКОМ ЯЗЫКЕ И КУЛЬТУРЕ

В докладе рассматриваются похвала, комплимент и лесть на материале датских телевизионных сериалов. Анализируются лексические и грамматические особенности данных речевых актов. Делается попытка выявить национально-специфическое своеобразие исследуемых единиц в датском языке, обусловленное определенными культурными ценностями.

А.М. Дементьева (МГЛУ)

\section{ОСОБЕННОСТИ ПЕРЕВОДА АНГЛИЙСКОЙ ЗВУКОИЗОБРАЗИТЕЛЬНОЙ ЛЕКСИКИ} НА ШВЕДСКИЙ И ФИНСКИЙ ЯЗЫКИ

В докладе рассматриваются особенности передачи звукоизобразительной лексики с английского на шведский и финский язык на примере перевода книги «Гарри Поттер и кубок огня». Выбор произведения обусловлен тем, что в нем содержится большое количество разнообразной звукоизобразительной лексики: в рассмотренных главах 31-35 было найдено 169 подобных слов. В докладе анализируются сходства и различия шведских и финских эквивалентов с учетом теории фоносемантики. Для сопоставления также привлекается результат исследования перевода указанного произведения на исландский язык.

\section{Е.Л. Жильцова (МГУ имени М.В. Ломоносова)}

\section{НАРЕЧИЯ-ИНТЕНСИФИКАТОРЫ В ШВЕДСКОМ ЯЗЫКЕ}

В докладе анализируются шведские наречия, которые, употребляясь при прилагательных, указывают на крайне высокую степень проявления выражаемого ими качества. В шведском языке такие наречия образуются от качественных прилагательных, обозначающих большие размеры (väldig «огромный»), крайне негативную оценку (hemsk «ужасный») или имеющих отношение к нечистой силе (jävlig «дьявольский»). Однако в составе рассматриваемых наречий происходит семантическое обесцвечивание производящей основы прилагательного, и наречие приобретает исключительно усилительную функцию. При частом употреблении эмотивность, характерная для наречий-интенсификаторов, стирается, и они достаточно быстро заменяются новыми.

\section{Д.В. Кобленкова (ВГИК имени С.А. Герасимова) ОБРАЗ РАСПУТИНА В РОМАНЕ К.Ю. ВАЛЛЬГРЕНА «ЛИЧНОЕ ДЕЛО ИГРОКА РУБАШОВА»}

В романе К.Ю. Валльгрена, написанном в преддверии «миллениума», обобщается исторический опыт прошлого и прогнозируется возможное будущее. Автор использует образ России как символическую параллель для Европы, стоящей перед угрозой распада. Концептуальным центром представлений о России как стране «хронической катастрофы» становится личность Распутина, являющего собою парадоксальный разрыв между греховностью и святостью и выполняющего функции пророка, который не был услышан. Российский опыт призван, по Валльгрену, служить предупреждением трагических ошибок Европы и мотивировать поиски нового мессии, способного удержать мир от «грядущей катастрофы».

${ }^{1}$ Исследование выполнено при финансовой поддержке РФФИ в рамках научного проекта № 19-012-00146. 


\section{Е.В. Кравченко (МГУ имени М.В.Ломоносова) \\ СООТНОШЕНИЕ ПРОЗАИЧЕСКОГО И ПОЭТИЧЕСКОГО ЯЗЫКА В ДРЕВНЕИСЛАНДСКОМ ЭПИЧЕСКОМ НАРРАТИВЕ (НА ПРИМЕРЕ УПОТРЕБЛЕНИЯ СЛОВ, ОБРАЗУЮЩИХ СИНОНИМИЧЕСКУЮ СИСТЕМУ МОРЯ)}

В древнеисландских традиционных текстах обращает на себя внимание органичное соединение прозы и поэзии (ср. прозаические вставки в героических песнях «Старшей Эдды»), а актуальные малые прозаические формы сравнимы с актуальными жанрами эддической поэзии, написанными особым поэтическим размером. Иначе говоря, на фоне существующих основных повествовательных форм (большой и малой) в древнеисландском эпическом нарративе повсеместно утверждается проницаемость границы между прозой и поэзией, где под влиянием аллитерационного стихосложения происходит семантическая трансформация слов в условиях особой организации поэтической лексики. Интерес для анализа представляет варьирование в нарративе пространственных обозначений (в частности, наименований локусов, связанных с морем) внутри одного сюжета.

\section{О.Е. Красова (МГИМО МИД России)}

\section{О МЕТОДИКЕ ПРЕПОДАВАНИЯ ИНОСТРАННОГО ЯЗЫКА В НЕЯЗЫКОВОМ ВУЗЕ}

Концепция мультидисциплинарного подхода, основанная на методе обучения на основе реально существующих явлений и взаимосвязей между ними, хорошо сочетается с традиционными методами преподавания иностранных языков и дополняет их, особенно в неязыковом вузе, как на начальном, так и на продвинутом этапе обучения, как в качестве индивидуального, так и в качестве группового задания.

Этот относительно новый метод преподавания - явление-ориентированное, или, как его обычно называют, феномено-ориентированное, преподавание и обучение, явился продолжением различных научно-практических методик обучения и преподавания, направленных на решение одного конкретного задания.

\section{Е.В. Краснова (СПбГУ)}

\section{СОМАТИЗМЫ В ДАТСКОЙ ЯЗЫКОВОЙ КАРТИНЕ МИРА ${ }^{1}$}

Соматизмы, или обозначения частей тела, являются наиболее древней и наиболее важной составляющей картины мира любого народа. В докладе рассматриваются соматизмы, относящиеся к верхней части тела, а также анализируются случаи расхождения между датским и русским языками.

Э.Б. Крылова (МГУ имени М.В. Ломоносова)

ПРОБЛЕМА ОТГРАНИЧЕНИЯ МОДАЛЬНЫХ ЧАСТИЦ ОТ ДРУГИХ КЛАССОВ СЛОВ В ДАТСКОМ ЯЗЫКЕ

Рассматриваемая проблема имеет два аспекта: грамматически функциональной смежности модальных частиц с наречиями и прагматически функциональной смежности модальных частиц с модальными словами. Проблема отграничения целого ряда частиц от наречий является проблемой омонимии - полисемии: $d a$

\footnotetext{
${ }^{1}$ Исследование выполнено при финансовой поддержке РФФИ в рамках научного проекта № 19-012-00146.

${ }^{2}$ Исследование выполнено при финансовой поддержке РФФИ в рамках научного проекта № 19-012-00146.
} 
тогда и модальная частица $d a$, наречие $n o k$ достаточно и модальная частица $n o k$ и др. Модальные слова и модальные частицы объединяет то, что они выражают отношение говорящего к высказыванию, занимают одинаковые позиции в структуре предложения, могут изменять модальность всей пропозиции. Проводимый в докладе анализ позволяет выделить частицы в отдельный класс слов по целому ряду признаков: словообразовательных, морфологических, семантических, синтаксических, просодических и прагматических.

А.Н. Ливанова (СПбГУ)

НЕКОТОРЫЕ СООБРАЖЕНИЯ О ГЛАГОЛЕ ЕА В НОРВЕЖСКОМ ЯЗЫКЕ

В работах Елены Михайловны Чекалиной по грамматической семантике глаголов среди прочего подробно охарактеризованы перифрастические конструкции шведского глагола $f a ̊$ с инфинитивом. Неоднократно привлекал внимание иссле-

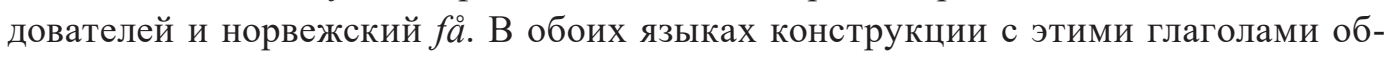
ладают рядом семантических и формальных особенностей. Сложны для описания и толкования также эквиваленты этих глаголов в других языках. В докладе рассматривается специфика норвежского глагола $f a ̊$ и возможность применения к норвежскому материалу анализа, предложенного Е.М. Чекалиной.

\section{M. Магнуссон (M. Magnusson; Шведский институт в Москве, САФУ имени М.В. Ломоносова; МГУ имени М.В. Ломоносова) \\ SPRÅKET I ANVÄNDNING - SPRÅKLIG FORM OCH SPRÅKLIG NORM}

Att förstå fenomenet språk är komplicerat och har många infallsvinklar. Språk faller inom många av de underområden som täcks av huvudområdet lingvistik med huvudaspekterna förmåga och användning - talad, skriven och förstådd. Här kommer vi att fokusera på användning av språket i talad och skriftlig form, primärt som ett socialt och pedagogiskt fenomen. Vi skall diskutera helt kort användning och inlärning av språk så väl som undervisning och huvudfokus kommer att vara funktionellt. Vi kommer också att beröra frågan om språk är ett rent mänskligt fenomen och ge exempel på olika former av språk.

\section{USAge OF LANGUAge - FormS AND NORMS}

Understanding the phenomenon of language is a complicated and many-facetted science. It falls into many sub-areas of the common discipline of linguistics, with the main aspects ability and usage - spoken, written and understood. Here we will focus on the usage of language in spoken and written form, as a social and educational phenomenon primarily. We will discuss usage and learning of language as well as teaching and the main focus will be functional. We will also touch upon the question whether language is a purely human phenomenon and give examples of different forms of language.

(Доклад на шведском языке, презентация на английском языке.)

И.В. Матыцина (МГУ имени М.В. Ломоносова)

\section{В ПОИСКАХ ИСТИНЫ ИЛИ ПОЧЕМУ ШВЕДЫ ВНОВЬ И ВНОВЬ ПЕРЕВОДЯТ БИБЛИЮ}

В докладе рассматриваются некоторые лексические трудности, с которыми сталкиваются переводчики в процессе работы над переводом Библии. Шведская Библия 2000 явилась результатом т. н. «коллаборативного перевода» с участием специали- 
стов-филологов, литераторов и переводчиков, а также представителей различных религиозных, образовательных и др. организаций. Толчок этому проекту дало развитие библеистики и изменения, произошедшие в языке в XX в., в результате чего прошлый перевод 1917 г., по мнению многих экспертов и пользователей, потерял свою актуальность. Однако и Библия 2000 стала объектом множественной критики, и к 2026 г. запланирована публикация еще одного перевода Нового Завета.

\section{T.А. Михайлова (МГУ имени М.В. Ломоносова) \\ ЭТУ ХОХЛАТУЮ ПТИЧКУ МЫ НАЗЫВАЕМ ЖАВОРОНКОМ...: О ЛИНГВИСТИЧЕСКОЙ АТРИБУЦИИ И ВОЗМОЖНОЙ ЭТИМОЛОГИИ ЛАТ. ALAUDA}

В докладе анализируется употребление латинской лексемы alauda, которая дала обозначения жаворонка во всех романских диалектах, за исключением балканского ареала. В латинских источниках лексема отмечается как галльская, однако в галльском нет ее надежной этимологии, к тому же она не имеет параллелей в островных кельтских языках. Исходя из предположения, что сочетания sermongallicus, linguagallica в латинском в начале н. э. могло обозначать как собственно галльский язык, так и региональный вариант латинского языка, распространенный в романизованной части Галлии в эпоху Империи, докладчик высказывает идею, что мы имеем дело с ареальным образованием латинского происхождения, искаженным фонетически. В качестве осторожного предположения дается лат. этимология: к глаголу alo 'кормить. растить, поднимать(ся)'. В таком случае, возможно, лексема представляет собой пассивное причастие alita>alida>alada (озвончение t в интервокальном положении, а также характерный галльский вокалический сингармонизм), семантически опирающееся на характерный хохолок, поднимающийся на голове у птицы, отмеченный Плинием (Hist. Nat. XI, 121) как характерная черта, выделяющая породу, распространенную на территории Галлии.

И.М. Михайлова (СПбГУ)

\section{ОТ ЛЬВА ТОЛСТОГО ДО ПЕТРА БАКУНИНА: РУССКИЙ СЛЕД В ТВОРЧЕСТВЕ ЛУИ КУПЕРУСА (1863-1923)}

Романы крупнейшего нидерландского писателя Луи Куперуса (1863-1923), переведенные на русский язык в эпоху Серебряного века и в наше время, нередко производят на русского читателя впечатление чего-то более близкого и привычного, чем книги других нидерландскоязычных авторов. В докладе будет рассмотрено влияние Льва Толстого на становление творчества Куперуса, во многом определившее характер его прозы, а также его увлечение русской теорией анархизма (М. Бакунин, П. Кропоткин) и теософией (Е. Блаватская).

И.М. Нетунаева (РГГУ)

\section{СЛОВООБРАЗОВАТЕЛЬНЫЕ МОДЕЛИ NOMINA ACTIONIS И NOMINA АСТI В ГОТСКОМ ЯЗЫКЕ}

В отличие от греческого языка, где девербативы (єклоүп́ избрание и те, кого избрали от єк- $\delta \dot{\gamma}($ выбирать) могут сочетать значения активного действия и его результата, в готском переводе происходит дифференциация nomina actionis (hauheins прославление от hauhjan возвеличивать), обозначающих центробежный процесс, и nomina acti (ga-waleins то, что избрано от waljan выбирать), обозначающих результат центростремительного действия (результативное состояние, пол- 
ноту осуществления действия или достигнутую цель). Решающую роль сыграл сукцессивный префикс $g a-$ : результативы, имея ту же парадигму, что и имена действия (i/ō-ж.), отличаются наличием в словообразовательной модели префикса $g a-$.

А.А. Немиева (МГУ имени М.В. Ломоносова)

ОБ ОСОБЕННОСТЯХ НЕКОТОРЫХ ИМЕН СУЩЕСТВИТЕЛЬНЫХ В ДАТСКОМ ЯЗЫКЕ ${ }^{1}$

В докладе будут рассмотрены существительные общего рода, которые, употребляясь с местоименными лексемами среднего рода, могут иметь другой лексико-семантический вариант. Речь идет о таких существительных, как familie (ceмья) - noget familie (родственники) и т. д.

Д.Б. Никуличева (Институт языкознания РАН; МГЛУ)

\section{АНТРОПОЦЕНТРИРОВАННАЯ ОРГАНИЗАЦИЯ ПРОСТРАНСТВА СРЕДСТВАМИ} ДАТСКИХ ПРОСТРАНСТВЕННЫХ НАРЕЧИЙ В ЗЕРКАЛЕ ПЕРЕВОДА ${ }^{2}$

Объектом исследования служат датские наречно-предложные сочетания, обозначающие местоположение и перемещение в пространстве. Методика состоит в сопоставлении художественных переводов на русский язык с датскими оригиналами и регистрации опущений и приращений смысла, связанных с пространственной ориентацией. Результатом является вывод о том, что, если в русском языке нюансируется ориентация относительно объектов внешнего мира и детализируется тип движения, то в датском языке наиболее важна антропоцентрированная ориентация действия относительно субъекта. Тем самым создается коммуникативный эффект пространственной эмпатии, противопоставленный эффекту темпорального дистанцирования, выраженного таксисными категориями датского глагола.

\section{Г.К. Орлова (МГИМО МИД России)}

\section{КИРСТЕН ТОРУП: «БОЛЬНЫЕ» ТЕМЫ ХХ ВЕКА}

Кирстен Торуп принадлежит к числу крупнейших писателей-реалистов в современной датской литературе. В двенадцати романах, созданных ею в период с 1973 по 2020 г., через фильтр индивидуального сознания проводятся основные «острые» темы, доминирующие в западноевропейском культурном контексте XX в. и касающиеся перемен в мироустройстве, оценки исторических событий, кардинальных изменений, произошедших в семейной и общественной жизни и повлекших за собой модификацию социальных ролей и моделей поведения и представлений о психическом и физическом благополучии человека.

\section{А.М. Поликарпов (директор НОЦ «Интегративное переводоведение приарктического пространства»; САФУ имени М.В. Ломоносова) \\ ИГНАТИЙ МИХАЙЛОВИЧ ИВАНОВСКИЙ - ПЕРЕВОДЧИК ШВЕДСКОЙ ПОЭЗИИ В ЗЕРКАЛЕ ИСТОРИИ ПЕРЕВОДА НА ПОМОРСКОМ СЕВЕРЕ}

Благодаря своим поэтическим переводам Игнатий Ивановский (1932-2016) познакомил русскоязычных читателей с творчеством многих шведских поэтов (Д. Андерссон, К.М. Бельман, Э.Г. Гейер, Л. Люсидор, Э.Ю. Стагнелиус, А. Стриндберг, Э. Тег-

${ }^{1}$ Исследование выполнено при финансовой поддержке РФФИ в рамках научного проекта № 19-012-00146.

${ }^{2}$ Исследование выполнено при финансовой поддержке РФФИ в рамках научного проекта № 19-012-00146. 
нер, Г. Фрёдинг, Н. Ферлин). В докладе анализируются три перевода, выполненные И.М. Ивановским со шведского языка на русский: «Крестьянин» Э.Г. Гейера, «Водяной» Э.Ю. Стагнелиуса и «Разгар лета зимой» А. Стриндберга. В связи с исследованиями истории перевода на Поморском Севере представляются важные сведения о жизни и переводческой деятельности И.М. Ивановского. Особое внимание уделяется жизни поэта и переводчика в 1962-1970 гг. в Архангельской области, где он работал учителем английского языка и директором школы в деревне Кехта, а затем в редакциях региональных газет.

Д.М. Радуйко (МГУ имени М.В. Ломоносова)

\section{ФРАЗЕОЛОГИЗМЫ С КОМПОНЕНТОМ-СОМАТИЗМОМ НА̊ND («РУКА») В ДАТСКОМ ЯЗЫКЕ В СОПОСТАВЛЕНИИ С РУССКИМ}

В научном сообщении рассматриваются семантические особенности фразеологических единиц с компонентом-соматизмом «рука» (hånd), выявленные в системах русского и датского языков. Приведены общие и специфические черты исследуемых языковых единиц, а также их семантические группы (рука как символ власти; рука как качественная характеристика умений; рука как способ приобретения благ и пр.), что позволяет выявить лингвокультуролические и этимологические особенности фразеологических единиц с компонентом-соматизмом «рука» (hånd) в русском и датском языках в сравнительном аспекте.

Е.Р. Сквайрс (МГУ имени М.В. Ломоносова)

БЕРЕСТА ДЛЯ ПОСЛЕДНЕЙ НАДЕЖДЫ

В год 70 -летия обнаружения первой берестяной грамоты на древнерусском языке (2021) открылась перспектива аналогичных посланий от западных партнеров Новгорода. Анализ языка, письма, жанра и стиля известного экземпляра берестяного послания 1570 года из шведского Ревеля позволяет апробировать ожидания историков и археологов в отношении Новгорода. Сопоставительный анализ аспектов тематики, структуры текста, техники письма на бересте показывает важные отличия исследуемого источника от новгородской традиции текстов на бересте.

\section{E.В. Терешко (Институт языкознания РАН;} МГУ имени М.В. Ломоносова)

\section{ЯЗЫК ПРОИЗВЕДЕНИЙ СОВРЕМЕННОЙ НИДЕРЛАНДСКОЙ ПРОЗЫ (HA ПРИМЕРЕ POMAHA «ZOMERVACHT» - JAAP ROBBIN)}

Доклад посвящен отличительным чертам нидерландского языка, которые характеризуют современную художественную прозу Нидерландов. В качестве иллюстративного материала выбран роман современного писателя Йапа Роббина «Zomervacht» (досл. «Летняя шубка»), вышедший в 2018 г. В докладе рассматриваются такие приемы, как кинематографическое построение текста, использование наименований объектов современной культуры и субкультур, неожиданный характер сравнений и др. 
T.А. Точтендаль-Салычева (директор Российско-шведского учебно-научного иентра РГГУ; почетный доктор Уппсальского университета, Швеция)

НОВОЕ НАПРАВЛЕНИЕ ИСТОРИЧЕСКИХ ИССЛЕДОВАНИЙ В ШВЕЦИИ ВТОРОЙ ПОЛОВИНЫ ХХ ВЕКА: МИКРОИСТОРИЯ

В 1960-1980-х гг. в Швеции произошла историографическая революция, главным следствием которой было появление новых исследовательских направлений. Историки начали писать труды по социальной истории, гендерной, глобальной, микроистории и новой политической истории. Французские и итальянские авторы дали импульс для развития микроисторических подходов в исследовательских практиках шведских историков. Прорыв в области микроистории состоялся в середине 1980-х гг. И первыми здесь были экономические историки, затем этот метод укоренился среди историков, писавших по гендерной тематике.

Ю.В. Филинова (МГУ имени М.В. Ломоносова)

ШВЕДСКИЕ МОДАЛЬНЫЕ ЧАСТИЦЫ NOG И VISST: СХОДСТВА И РАЗЛИЧИЯ

Доклад посвящен шведским модальным частицам nog и visst. Благодаря просодическим и синтаксическим особенностям употребления они стоят особняком в системе лексем, которые принято относить к этому классу. С одной стороны, nog и visst обладают схожей семантикой и во многих контекстах взаимозаменяемы, с другой - каждая из них имеет свои особые функции в тексте и дискурсе, для выявления которых требуется тщательный анализ предложения с частицей с учетом лингвистического и экстралингвистического контекстов.

А.В. Циммерлинг (Государственный институт русского языка имени А.С. Пушкина; Институт языкознания РАН)

ИМЕНА И СООБЩЕСТВА: ВАРЯГИ, КОЛБЯГИ И ВИКИНГИ ВОКРУГ БАЛТИКИ

В докладе обсуждаются употребления заимствованных слов ВАРЯГИ, КОЛБЯГИ и ВИТЯЗИ в древнерусских и старорусских текстах на фоне употребления источников этих слов в древнескандинавских текстах.

\section{Л.С. Чекин (Научно-исследовательский ичентр «АИРО-ХХІ») \\ НОВЫЕ ДАННЫЕ ОБ ИЗДАНИИ ПЕРВОГО АКАДЕМИЧЕСКОГО РУССКО-ШВЕДСКОГО СЛОВАРЯ}

Сообщение посвящено первому академическому русско-шведскому словарю незаконченному делу жизни Эрика Густава Эрстрёма (1791-1835). Ранее были известны и изучены С.Л. Гонобоблевой только несколько корректурных листов первого тома словаря. Автору сообщения удалось обнаружить полный экземпляр первого тома в Национальной библиотеке Швеции. Выдвигается гипотеза о том, что в решении издать словарь под эгидой Российской академии ключевую роль сыграло знакомство великого датского лингвиста Расмуса Кристиана Раска, который покровительствовал Эрстрёму, с президентом Российской академии А.С. Шишковым. 
Древнеисландское существительное maðr (соврем. maður) употреблялось преимущественно в значении «человек», а также имело контекстуальные значения «муж» и «мужчина». Все эти значения сохраняются и в современном языке, при этом два последних соотносятся супотреблением слова в составе композитов: karlmaður «мужчина» (= «мужской человек»; cp. kvenmaður «женщина»= «женский человек»), eiginmaður «муж» (= «свой мужчина»; cp. eiginkona «жена»= «своя женщина»).

Кроме того, под влиянием немецкого языка из существительного «человек» образовалось неопределенное местоимение, которое имеет обобщенное значение. Однако граница между maður-существительным и maður-местоимением проницаема, что прежде всего связано с сохранением у местоимения субстантивной парадигмы, за исключением определенной формы, и отсутствием в исландском языке неопределенного артикля.

Б. Энглунд-Димитрова (B. Englund-Dimitrova; Институт устного и письменного перевода; Стокгольмский университет)

NÄR STOCKHOLM FIRADE EN NY RYSK TSAR TILL TONER AV DEN SVENSKA MUSIKENS FADER: VAD SÄGER KÄLLORNA OM GOLOVIN MUSIKEN?

«Den svenska musikens fader» Johan Helmich Roman (1694-1758) var kompositör och hovkapellmästare men även översättare, med kunskaper i ett flertal språk, dock inget slaviskt. Hans enda kända ryska anknytning är Golovin musiken, skriven till en fest 1728 i Stockholm som den ryske ambassadören Nikolaj Fjodorovitj Golovin ordnade för att fira kröningen av tsar Peter II av Ryssland. I mitt bidrag vill jag källkritiskt belysa och diskutera läget beträffande primär källor till information om tillställningen och dess musik och hur nyare texter framställer evenemanget.

\section{Stockholm Celebrations of a New Russian Tsar accompanied by Tunes by the Father of Swedish Music: What do Sources Say about The Golovin Music?}

«The Father of Swedish music» Johan Helmich Roman (1694-1758) was a composer and leader of the orchestra of the Royal Swedish Court, but also a translator working from several languages (English, German, French, Italian, Latin). His only known Russian connection is the so called Golovin Music, which was composed for a festivity in Stockholm 1728 organized by the Russian ambassador N.F. Golovin to celebrate the recent coronation of Tsar Peter II of Russia. The presentation will discuss available historical and later sources on the event, analyzing critically the information given.

(Доклад на шведском языке, презентация на английском языке.) 